\title{
Salespeople's Renqing Orientation, Self-esteem, and Selling Behaviors: An Empirical Study in Taiwan
}

\author{
Ming-Hong Tsai · Shu-Cheng Steve Chi • \\ Hsiu-Hua Hu
}

Published online: 1 March 2009

(c) The Author(s) 2009. This article is published with open access at Springerlink.com

\begin{abstract}
Purpose The purpose of this study was to investigate how salespeople's renqing orientation and self-esteem jointly affect their selling behavior.

Design/Methodology/Approach Data were obtained from a survey of salespeople from 17 pharmaceutical and consumer-goods companies in Taiwan $(n=216)$.

Findings Salespeople's renqing orientation (i.e., their propensity to adhere to the accepted norm of reciprocity) compensates the negative effect of self-esteem on their selling behaviors, such as adaptive selling and hard work. Implications Our study results underscore the critical role of the character trait of renqing orientation in a culture emphasizing a norm of reciprocity. Therefore, it would be useful to consider a strategy of recruiting salespeople with either a high self-esteem or a combination of high renqing orientation and low self-esteem.

Originality/Value The existing literature of industrial/ organizational psychology and marketing primarily relies on constructs that are derived from Western cultural contexts. However, the present paper extended these literatures by investigating the possible joint effects of self-esteem
\end{abstract}

\author{
M.-H. Tsai ( $\square)$ \\ University of California, 11140 Rose Ave. Apt 307, \\ Los Angeles, CA, USA \\ e-mail: mtsai@anderson.ucla.edu \\ S.-C. S. Chi \\ Department of Business Administration, National Taiwan \\ University, 1, Sec. 4, Roosevelt Road, Taipei, Taiwan \\ e-mail: n136@management.ntu.edu.tw
}

H.-H. Hu

Department of International Business, Ming Chuan University, 250, Sec. 5, Chung Shan N. Road, Taipei, Taiwan

e-mail: shhu@mcu.edu.tw with a trait originated from the Chinese culture on salespeople's selling behaviors.

Keywords Self-esteem - Renqing orientation . Selling behavior - Taiwan

\section{Introduction}

\section{Guanxi-Building in Chinese Societies}

Networks of informal relationships are one of the major characteristics of business and social activities in Asian regions such as Mainland China, Hong Kong, Korea, Japan, and Taiwan (Kienzle and Shadur 1997; Gerlach 1987). Consequently, organizational members often need to make use of their interpersonal relationships to improve job performance. Salespeople, in particular, consistently interact with customers, and their sales performance largely depends upon how successfully they translate interpersonal relationships into actual purchases. The now well-known Chinese term guanxi describes interpersonal dynamics that draw on a web of connections with the purpose of securing particular favors in personal relations (Park and Luo 2001). The Chinese culture of Confucianism has institutionalized this "norm of reciprocity" into everyday lives. That is, personal guanxis describes an individual's particular, reciprocal exchanges with another person (e.g., a relative, a friend, a customer, a business partner, a colleague, or a boss/ subordinate, etc.). Theorists have suggested that it is the anticipation of repayment that motivates Chinese people to offer one another favors (e.g., Hwang 1987). For instance, a Chinese person seeking a business opportunity may activate his or her guanxi networks in the hope that an earlier favor paid to someone else will generate new opportunities. 
Given that every Chinese person may exchange favors under an accepted cultural norm, both the giver and the recipient of favors expect the other party to continue these reciprocal exchanges in the future. As an illustration, during special occasions such as the Chinese New Year, weddings, birthdays, or festivals, Chinese people may feel duty-bound to give presents to individuals of priority within their guanxi network. This gift-giving is a large part of guanxi-building and maintenance (Hwang 1987). Put another way, maintaining networks of guanxis implies continual exchanges of favors (Chen 1995).

\section{Renqing Orientation as a Personality Trait}

Nevertheless, not every Chinese person follows this cultural norm in the same manner. Some may have a higher tendency of giving gifts to those who have helped them in the past, for example, but others may not. Recent articles by Cheung et al. $(1996,2001)$ proposed and showed that Chinese people act differently when facing decisions about exchanges of favors. Cheung et al. $(1996,2001)$ termed the degree to which a person abides to rules of reciprocity regarding favor exchanges as "renqing orientation". They also developed a personality inventory-the Chinese Personality Assessment Inventory (CPAI) - to examine such individual differences among Chinese people (Cheung et al. 1996). Renqing was one of the three personality constructs chosen in consideration of Chinese culture (the other two were face and harmony). Their study findings evidenced the psychometric properties of CPAI and its reliability and validity.

To date, only few studies have utilized the renqing orientation construct and examined its effects on other variables. One study by Chan (2002) found that tutors' renqing orientation positively affected students' perceived teaching effectiveness, such as motivation, presentation, and attitude, at a distance-learning institution in Hong Kong. Zhang and Bond (1998) discovered a positive relationship between college students' renqing orientation and their filial piety. In their findings, students with a high renqing orientation had a high tendency to provide for the material and mental well-being of their aged parents, in order to ensure the continuity of the family line, and to perform ceremonial duties of ancestral worship.

\section{Linking Renqing Orientation to Selling Behaviors}

The present study proposed a direct link between salespeople's renqing orientation and their selling behaviors. We followed Weitz et al.'s (1986) classification of selling behaviors. They identified two general types of selling behaviors: adaptive selling and hard work (see also Levy and Sharma 1994; Sujan 1986; Weiner 1980; Sujan et al. 1994).

\section{Adaptive Selling}

The first type of selling behavior is "adaptive selling", or "the altering of sales behaviors during a customer interaction, or across customer interactions, based on perceived information about the nature of the selling situation" (Levy and Sharma 1994, p. 39). Research has shown that excellent sales representatives often alter their selling behaviors on the basis of situational considerations (Sujan et al. 1994; Leong et al. 1989). That is, these salespeople will try to understand the need of their customers, select the best sales strategies for these customers, and recommend products that satisfy these customers' particular needs (Weitz 1978; Weitz et al. 1986; Lambert et al. 1990).

We proposed a direct relationship between salespeople's renqing orientation and their degree of adaptive selling. Specifically, we suggested that salespeople with a high renqing orientation are especially sensitive to their customers' needs. Thus, relative to salespeople with a low renqing orientation, it is likely that salespeople with a high renqing orientation will be more flexible in response to the needs of individual customers in expectation that these customers will reciprocate attentiveness with purchases.

\section{Hard Work}

Another type of selling behavior, "hard work" describes "the overall amount of effort that a salesperson devotes to his or her work" (Sujan et al. 1994, p. 40). Empirical evidence has shown that high-performing salespeople are usually those who work very hard at their jobs (Churchill et al. 1985; Sujan et al. 1994). Sujan et al. (1994) suggested that these successful salespeople tend to be persistent at selling, devote a great deal of effort to their work, and continue their selling effort even in the face of failure.

Again, we proposed that salespeople with a high renqing orientation will be sensitive to the giving and receiving of social favors based on the implicit social norm (Luo 1997). These salespeople are inclined to work hard to understand and satisfy the needs of their customers. That is, we proposed that individuals with a high renqing orientation tend to work hard to meet their customers' needs. Therefore, relative to salespeople with a low renqing orientation, it is likely that salespeople with a high renqing orientation will devote more effort and be persistent in satisfying the needs of their customers, expecting these customers to reciprocate their efforts with purchases.

In sum, a high renqing orientation elevates a salesperson's motivation to cultivate customer relationships, be more flexible in meeting customers' needs, and work hard to make sales. These salespeople have a high expectation of receiving payoffs for their efforts. That is, they believe that if they invest time, effort, and resources in building 
and maintaining relationships with customers, their efforts will translate into purchases. Based on the preceding discussion, we proposed the following hypotheses:

Hypothesis 1 A positive relationship exists between a salesperson's renqing orientation and his or her adaptive selling.

Hypothesis 2 A positive relationship exists between a salesperson's renqing orientation and how hard he or she works at selling.

\section{The Moderating Role of Self-esteem}

In addition, we proposed that the positive effects of salespeople's renqing orientation on their selling behaviors are likely to vary depending upon their levels of self-esteem. Scholars have defined self-esteem as the degree to which people perceive themselves to be capable, significant, and worthy (Coopersmith 1967; Marsh 1993; Wells and Marwell 1976). Relative to people with low self-esteem, individuals with high self-esteem tend to access more positive thoughts about themselves after a failure and tend to maintain a positive focus (Taylor and Brown 1988). Additionally, when compared with those with low self-esteem, individuals with high self-esteem are better able to manage stressful situations and perceive the work environment as controllable. Sager (1991), for example, discovered a negative relationship between the self-esteem of salespeople and their level of job-related stress. Similarly, Burton et al. (2005) found that individuals with higher self-esteem were more likely to respond to a perceived injustice aggressively.

This study sought to investigate the possible joint effects of self-esteem (a core concept in a person's self-perception) with renqing orientation (a trait that is crucial within Chinese culture) on salespeople's selling behaviors. The examination of such effects is critical because, on the one hand, it may enhance our understanding of the boundary condition of the effects of self-esteem on individual behaviors and, on the other hand, the dynamics of selfesteem with another trait that is more relevant to the embedded culture. We suspected that, for salespeople with high self-esteem, the relationship between renqing orientation and selling behaviors would be relatively weak. On the contrary, for salespeople with low self-esteem, the relationship between renqing orientation and selling behaviors is relatively strong. We borrowed Brockner's (1988) concept of "behavioral plasticity" to explain this proposition.

According to Brockner (1988), people respond differently to external factors, such as influence attempts from other people. Brockner suggested that individuals with low self-esteem tend to be more "behaviorally plastic", or reactive, than those with high self-esteem. Research findings have supported this behavioral plasticity hypothesis in the realm of feedback effects, peer-group interaction, and workplace socialization (e.g., Ganster and Schaubroeck 1991b; Kahn and Byosiere 1992). In addition, individuals with low self-esteem are highly uncertain about their own work attitudes and behaviors (Brockner 1988), and they have a strong need for approval from others (e.g., superiors or customers). As a result, they often rely on others' actions and suggestions to perform their own job activities (Pierce et al. 1993). Samad (2007), for example, found that, for low self-esteem employees, having an open personality had an insignificant effect on psychological empowerment. That is, low self-esteem individuals would not be empowered even by a high degree of openness, but would prefer to rely on directions from above.

It is likely that salespeople with low self-esteem and high renqing orientation make use of their social connections to solve their problems rather than relying on their own abilities and skills. According to Hobfoll and Leiberman's (1987) arguments, a person with plenty of social resources will be able to make effective use of these resources when the situation demands them. Consequently, low self-esteem salespeople will make a better psychological adjustment, if they utilize their social resources when facing misfortune (Baumeister 1998).

Accordingly, renqing orientation was likely to have a greater impact on the selling behaviors of those with low selfesteem and a smaller impact on the selling behaviors of those with high self-esteem. Salespeople with high self-esteem often are adaptive in stressful situations and engage in active coping and planning (Pierce et al. 1993). Therefore, their selling behaviors emerge from more than just a concern for the norm of reciprocal exchange. On the contrary, among salespeople with low self-esteem, those with a high renqing orientation are more willing to engage in selling behaviors for the purpose of winning customers' trust and purchases. They are motivated by the norm of reciprocity, rather than a sense of their own ability, and expect their favors to generate high sales performance. Therefore, we proposed the following:

Hypothesis 3 Self-esteem mitigates the positive relationship between the renqing orientation of salespeople and their adaptive selling.

Hypothesis 4 Self-esteem mitigates the positive relationship between the renqing orientation of salespeople and their hard work in selling.

\section{Methods}

\section{Sample}

The participants in this study were salespeople at 17 pharmaceutical and consumer-goods companies in Taiwan. 
Survey questionnaires were distributed to participants through the companies' human resource offices. The participants were told that the purpose of the research was to better understand salespeople's behaviors; they were assured that the study was anonymous and that only aggregated data would be reported. Each participant completed the questionnaire and returned it in a sealed envelope to their company's human resource manager, who then forwarded it to the researcher. Of the 400 questionnaires distributed, 216 , or $54 \%$, were returned. About two thirds of the participants $(67.6 \%)$ were male. The average age of participants was 35, and they had an average of about 9 years of selling experience.

\section{Measures}

\section{Renqing Orientation}

We used Cheung et al.'s (1996) 11-item scale to assess salespeople's renqing orientation. A sample item is: "When dealing with institutions, things can work out more smoothly through the connections of friends working inside".

The reliability and validity of the renqing scale have been examined in several studies. Its internal consistency coefficients (Cronbach's alphas) ranged from .55 to .74 (Cheung et al. 1996, 2003). Its test-retest correlation coefficients were statistically significant (Cheung et al. 1996). The convergent validity of the scale was examined by comparing the patterns of its correlation coefficients with the Minnesota multiphasic personality inventory (MMPI-2; Butcher 1996; Cheung and Zhang 2004). The scale demonstrated reasonable patterns that were associated with the MMPI-2 scales. Specifically, renqing orientation was negatively related to "conversion hysteria" and was positively related to "schizophrenia" and "hypomania" in the MMPI-2 clinical scales. Cheung et al. (2003) further examined the clinical validity of the CPAI in two studies that included 167 male prisoners in Hong Kong and 339 psychiatric patients in mainland China. According to their logistic regression results, the renqing scale was a useful tool in distinguishing psychiatric patients from the normative sample in China and in distinguishing male prisoners from normal male respondents in Hong Kong.

\section{Self-esteem}

We used Rosenberg's (1965) 10-item scale to assess salespeople's self-esteem. A sample item is: "On the whole, I am satisfied with myself". Higher scores indicate a higher degree of self-esteem.

\section{Adaptive Selling}

We used Spiro and Weitz's (1990) 12-item measure of adaptive selling to assess salespeople's adaptive selling. A sample item is: "I vary my sales style from situation to situation".

\section{Working Hard}

We used Sujan et al.'s three-item measure (Sujan et al. 1994) to assess salespeople's degree of hard work in jobrelated activities. A sample item is: "I work untiringly at selling a customer until I get an order".

Among our measures, the Renqing orientation scale was developed in Mandarin Chinese, while the other scales were originally written in English, translated by the researchers into Chinese, then back-translated into English (Brislin et al. 1973) to assure their correct meanings. We used a six-point Likert scale $(6=$ strongly agree, $1=$ strongly disagree) for all of the above scales, asking the respondents to indicate their degree of agreement.

In addition to these measures, we asked respondents to report their sex, age, education, and past selling experiences (in years) as control variables. Research has shown that these variables may be related to salespeople's selling behaviors (e.g., Bernard 1981; Goolsby et al. 1992; Levy and Sharma 1994).

\section{Results}

The descriptive statistics, reliability estimates, and correlation coefficients of our study measures are shown in Table 1. All of the Cronbach's alpha coefficients for the scales were above the acceptable level of .70 (Nunnally 1978).

We tested the hypotheses using multiple regression analysis. We mean-centered the predictors (i.e., renqing orientation and self-esteem) before multiplying them in order to minimize multi-collinearity between the interaction term and its components, as recommended by Aiken and West (1992). In the regression models, we first entered the four control variables (sex, age, past selling experience, and education).

In our results, Hypotheses 1 and 2 were not supported (see Table 2). That is, renqing orientation did not have a significant positive relationship with adaptive selling and hard work $(p s>.05)$.

Hypotheses 3 and 4 proposed that self-esteem mitigates the relationship of renqing orientation with adaptive selling and with hard work. As shown in Table 2, we found significant and negative coefficients of the renqing orientation $\times$ self-esteem interaction term on adaptive selling 
Table 1 Means, standard deviations, scale reliabilities, and correlations

\begin{tabular}{|c|c|c|c|c|c|c|c|c|c|c|c|}
\hline Variable & Mean & $\mathrm{SD}$ & 1 & 2 & 3 & 4 & 5 & 6 & 7 & 8 & 9 \\
\hline Gender & 1.32 & .47 & - & & & & & & & & \\
\hline Age & 35.21 & 9.50 & -.44 & - & & & & & & & \\
\hline Education & 3.13 & .84 & -.01 & .00 & - & & & & & & \\
\hline Experience & 8.69 & 7.89 & -.36 & .91 & -.09 & - & & & & & \\
\hline Renqing orientation & 3.84 & .55 & -.08 & -.10 & .24 & -.20 & $(.81)$ & & & & \\
\hline Self-esteem & 4.51 & .53 & .09 & .15 & .05 & .22 & -.09 & $(.83)$ & & & \\
\hline Adaptive selling & 3.47 & .60 & -.25 & .31 & -.07 & .27 & .01 & .32 & .14 & (.88) & \\
\hline Hard work & 3.87 & .62 & -.14 & .34 & -.03 & .33 & .00 & .40 & .40 & .48 & $(.71)$ \\
\hline
\end{tabular}

Correlations greater than .13 are significant at the .05 level, two-tailed; those greater than .20 are significant at the .01 level; those greater than .22 are significant at the .001 level; scale reliabilities are on the diagonal

For gender, male $=1$, female $=2$

Table 2 Moderated regression models

\begin{tabular}{|c|c|c|c|c|c|}
\hline \multirow[t]{2}{*}{ Dependent variables } & \multicolumn{3}{|c|}{ Adaptive selling } & \multicolumn{2}{|c|}{ Hard work } \\
\hline & (1) & \multicolumn{2}{|l|}{ (2) } & (1) & (2) \\
\hline Adjusted $R^{2}$ & .20 & \multicolumn{2}{|l|}{.22} & .23 & .26 \\
\hline$R^{2}$ change & .22 & \multicolumn{2}{|l|}{.02} & .25 & .03 \\
\hline$F$ & 9.97 & \multicolumn{2}{|l|}{9.70} & 11.66 & 11.72 \\
\hline$d f$ & 6 & \multicolumn{2}{|l|}{7} & 6 & 7 \\
\hline$N$ & 216 & \multicolumn{2}{|l|}{216} & 216 & 216 \\
\hline \multicolumn{2}{|l|}{ Variable } & $\beta$ & $\beta$ & $\beta$ & $\beta$ \\
\hline \multicolumn{2}{|l|}{ Gender } & $-.18 * *$ & $-.17 * *$ & -.04 & -.03 \\
\hline \multicolumn{2}{|l|}{ Age } & $.40^{*}$ & $.43 *$ & $.32 *$ & $.35^{*}$ \\
\hline \multicolumn{2}{|l|}{ Education } & .12 & .13 & .07 & .09 \\
\hline \multicolumn{2}{|l|}{ Experience } & -.24 & -.27 & -.05 & -.08 \\
\hline \multicolumn{2}{|l|}{ Renqing orientation } & .05 & .05 & .07 & .08 \\
\hline \multicolumn{2}{|l|}{ Self-esteem } & $.34 * * *$ & $.32 * * *$ & $* .38 * * *$ & $.35^{* * *}$ \\
\hline \multicolumn{3}{|c|}{ Renqing orientation $\times$ self-esteem } & $-.16^{*}$ & & $-.18 * *$ \\
\hline
\end{tabular}

For gender, male $=1$, female $=2$

$* p<.05, * * p<.01, * * * p<.001$

$(\beta=-.16, p<.05)$ and on hard work $(\beta=-.18$, $p<.01)$. We examined these interaction effects by looking at the regression weights (simple slopes) of self-esteem at one standard deviation above and below the mean score of renqing orientation (see Figs. 1, 2). As predicted, the regression coefficients of renqing orientation with adaptive selling $(\beta=.22, p<.05)$ and with hard work $(\beta=.26$, $p<.001)$ were statistically significant when self-esteem was low, but not when it was high $(p>.05)$. These results suggest that a high level of self-esteem reduces the positive effect of renqing orientation on selling behaviors. By contrast, a low level of self-esteem facilitated the effects of renqing orientation on selling behaviors. In addition, we found that self-esteem had a positive relationship with adaptive selling $(\beta=.34, p<.001)$ and hard work $(\beta=.38, p<.001)$.

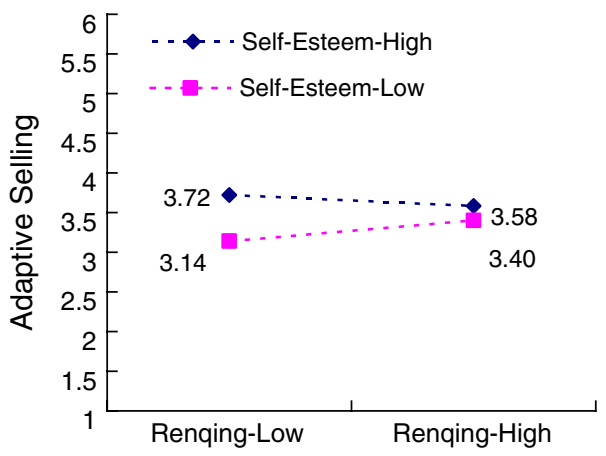

Fig. 1 Interaction effects between renqing orientation and selfesteem on adaptive selling

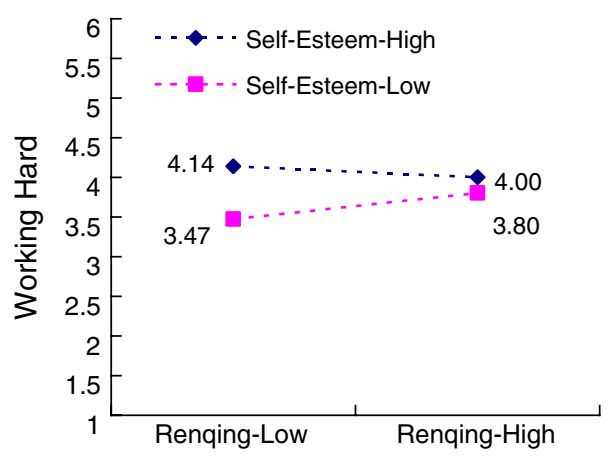

Fig. 2 Interaction effects between renqing orientation and selfesteem on hard work

Lastly, we discovered two additional findings from the data. First, we found a positive correlation between education and renqing orientation $(r=.24, p<.001)$, but we did not find significant correlation between education and selling behaviors $(p>$.05). Second, we found a negative correlation between selling experience and renqing orientation $(r=-.20, p<.01)$, while we found positive correlations between selling experience and selling behaviors (for adaptive selling, $r=.27, p<.001$; for hard work, $r=.33, p<.001)$. 


\section{Discussion}

To our knowledge, no study has yet examined relationships among individuals' renqing orientation, self-esteem, and task-related behaviors. Our findings demonstrated an interplay of self-esteem and renqing orientation for Chinese salespeople in business environments. However, our data did not find the expected positive relationship between renqing orientation and selling behaviors. It is likely that the two types of selling behavior are mainly related to work motivation (e.g., obtaining orders from customers or altering selling strategies when necessary) rather than to long-term business relationships. For example, the salespeople, who were high in renqing orientation might agree to a delay in customer payment or promise small gifts with purchase in expectation of reciprocal returns for these favors; however, such behaviors might not increase salespersons' motivation to obtain orders from customers or to adopt different strategies in different situations.

Our study results showed evidence that self-esteem had a mitigating role on the relationship between renqing orientation and selling behaviors. When compared with salespeople with low self-esteem, those with high selfesteem tended to engage in a lower degree of adaptive selling and hard work. Our results supported Brockner's (1988) behavioral plasticity hypothesis, which states that individuals with low self-esteem have a higher tendency to accommodate customers' needs than do individuals with high self-esteem (Brockner 1988; Ganster and Schaubroeck 1991a; Kahn and Byosiere 1992).

Two additional findings from the data must be noted. First, we found a positive correlation between education and renqing orientation, but no correlation between education and selling behaviors. It may be that the higher education of Chinese people helps to nurture their preferences for abiding by the social obligation of reciprocity. However, the higher education of salespeople may not be helpful with regard to their selling behaviors. Second, we found a negative correlation between selling experience and renqing orientation, but positive correlations between selling experience and selling behaviors. These findings are interesting. Our data showed that senior salespeople tended to have a lower level of renqing orientation and higher degrees of selling behaviors. One possible reason is that the salespeople, who have been promoted are those who have demonstrated effective selling behaviors (working smart and working hard), rather than those who have focused on abiding cultural norms. Another possible reason is that those who have a higher level of renqing orientation might have successfully utilized their social connections and, therefore, followed a broader career path beyond their initial sales jobs.
Our study makes two contributions to the business-psychology literature and management practice. First, the existing literature of industrial/organizational psychology and marketing primarily relies on constructs that are derived from Western cultural contexts. We extended these literatures by investigating the possible joint effects of selfesteem with a trait originated from the Chinese culture on salespeople's selling behaviors. Second, the increased globalization of business environment has heightened the importance of cross-cultural understanding. Consequently, our study has an important practical implication: helping international managers, who wish to do business in Chinese contexts to better understand, how cultural traits are relevant in sales situations. That is, it is useful to know that salespeople's renqing orientation can compensate for the positive effects of self-esteem on selling behaviors. Our study results underscore the critical role of the character trait of renqing orientation in a culture emphasizing a norm of reciprocity. Therefore, it would be useful to consider a strategy of recruiting salespeople with either a high self-esteem or a combination of high renqing orientation and low selfesteem.

\section{Study Limitations and Future Research Directions}

This study has several limitations that need to be addressed. First, our sample was made up of salespeople from only pharmaceutical and consumer-goods companies, limiting the generalizability of our results; future research may want to include salespeople from other industries. Second, our study was done in Taiwan, which limits the generalizability of our study results to different cultural settings. Future research may want to include salespeople in other countries or regions. Third, all our data were obtained from self-report survey questions. Thus, our findings may have the problem of commonmethod variance (i.e., variance attributable to the measurement method rather than to the constructs that the measures represent; Podsakoff et al. 2003). A final limitation is that we did not measure the salespeople's sales performance. Many studies have shown a strong correlation between sales performance and adaptive selling or hard work in selling (Leong et al. 1989; Sujan et al. 1994). Therefore, it would be fruitful for us to obtain a more objective measure of sales performance to explore a relationship among renqing orientation, self-esteem, and sales performance.

Open Access This article is distributed under the terms of the Creative Commons Attribution Noncommercial License which permits any noncommercial use, distribution, and reproduction in any medium, provided the original author(s) and source are credited. 


\section{References}

Aiken, L. S., \& West, S. G. (1992). Multiple regressions: Testing and interpreting interactions. Newbury Park, CA: Sage.

Baumeister, R. F. (1998). The self. In D. T. Gilbert, S. T. Fiske, \& G. Lindzey (Eds.), Handbook of social psychology (4th ed., Vol. 2, pp. 680-740). New York, NY: McGraw-Hill.

Bernard, J. S. (1981). The female world. New York, NY: The Free Press.

Brislin, R. W., Lonner, W. J., \& Thorndike, R. M. (1973). Crosscultural research models. New York, NY: Wiley.

Brockner, J. (1988). Self-esteem at work: Research, theory, and practice. Lexington, MA: Heath.

Burton, J. P., Mitchell, T. R., \& Lee, T. W. (2005). The role of selfesteem and social influence in aggressive reactions to interactional injustice. Journal of Business and Psychology, 20, 131170. doi:10.1007/s10869-005-6995-8.

Butcher, J. N. (Ed.). (1996). International adaptations of the MMPI2: A handbook of research and applications. Minneapolis, MS: University of Minnesota Press.

Chan, B. (2002). A study of the relationship between tutor's personality and teaching effectiveness: Does culture make a difference? International Review of Research in Open and Distance Learning, 3, available online at http://www.irrodl. org/index.php/irrodl/article/view/110/190.

Chen, M. (1995). Asian management systems. Chinese, Japanese and Korean styles of business. Thunderbird/Routledge series in International Management.

Cheung, F. M., \& Zhang, J. X. (2004). Convergent validity of the Chinese personality assessment inventory and the Minnesota multi-phasic personality inventory-2: Preliminary findings with a normative sample. Journal of Personality Assessment, 82, 92103. doi:10.1207/s15327752jpa8201_14.

Cheung, F. M., Leung, K., Fan, R. M., Song, W. Z., Zhang, J. X., \& Zhang, J. P. (1996). Development of the Chinese personality assessment inventory. Journal of Cross-Cultural Psychology, 27, 181-199. doi:10.1177/0022022196272003.

Cheung, F. M., Leung, K., \& Zhang, J. X. (2001). Indigenous Chinese personality constructs: Is the five-factor model complete? Journal of Cross-Cultural Psychology, 32, 407-433. doi: 10.1177/0022022101032004003.

Cheung, F. M., Kwong, J. Y. Y., \& Zhang, J. X. (2003). Clinical validation of the Chinese personality assessment inventory (CPAI). Psychological Assessment, 15, 89-100. doi:10.1037/ 1040-3590.15.1.89.

Churchill, G. A., Jr, Ford, N. M., Hartley, S. W., \& Walker, O. C. (1985). The determinants of salesperson performance: A metaanalysis. Journal of Marketing Research, 22, 103-118. doi: $10.2307 / 3151357$.

Coopersmith, S. (1967). The antecedents of self-esteem. New York, NY: Freeman.

Ganster, D. C., \& Schaubroeck, J. (1991a). Work stress and employee health. Journal of Management, 17, 235-271. doi:10.1177/ 014920639101700202.

Ganster, D. C., \& Schaubroeck, J. (1991b). Role stress and worker health: An extension of the plasticity hypothesis of self-esteem. Journal of Social Behavior and Personality, 6, 349-360.

Gerlach, M. (1987). Business alliances and the strategy of the Japanese firm. California Management Review, 30, 12-142.

Goolsby, J. R., Lagace, R. R., \& Boorom, M. L. (1992). Psychological adaptiveness and sales performance. Journal of Personal Selling \& Sales Management, 12, 51-66.

Heine, S. J. (2003). Making sense of East Asian self-enhancement. Journal of Cross-Cultural Psychology, 34, 596-602. doi: $10.1177 / 0022022103256481$
Hobfoll, S. E., \& Leiberman, J. R. (1987). Personality and social resource in immediate and continued stress resistance among women. Journal of Personality and Social Psychology, 52, 18 26. doi:10.1037/0022-3514.52.1.18.

Hwang, K. K. (1987). Face and favor: The Chinese power game. American Journal of Sociology, 92, 944-974. doi:10.1086/ 228588.

Kahn, R. L., \& Byosiere, P. (1992). Stress in organizations. In M. D. Dunnette \& L. M. Hough (Eds.), Handbook of industrial and organizational psychology (2nd ed., Vol. 3, pp. 571-650). Palo Alto, CA: Consulting Psychologists.

Kienzle, R., \& Shadur, M. (1997). Developments in business networks in East Asia. Management Decision, 35, 23-32. doi: 10.1108/00251749710160151.

Lambert, D. M., Marmorstein, H., \& Sharma, A. (1990). The accuracy of salesperson's perceptions of their customers: Conceptual examination and empirical study. Journal of Personal Selling \& Sales Management, 12, 51-66.

Leong, S. M., Busch, P., \& John, D. R. (1989). Knowledge bases and salesperson effectiveness: A script-theoretic analysis. Journal of Marketing Research, 26, 164-178. doi:10.2307/3172603.

Levy, M., \& Sharma, A. (1994). Adaptive selling: The role of gender, age, sales experience, and education. Journal of Business Research, 31, 39-47. doi:10.1016/0148-2963(94)90044-2.

Luo, Y. (1997). Guanxi and performance of foreign-invested enterprises in China: An empirical inquiry. Management International Review, 37, 51-70.

Marsh, H. W. (1993). Relations between global and specific domains of self: The importance of individual importance, certainty, and ideals. Journal of Personality and Social Psychology, 65, 975992. doi:10.1037/0022-3514.65.5.975.

Nunnally, J. C. (1978). Psychometric theory. New York, NY: McGraw-Hill.

Park, S. H., \& Luo, Y. (2001). Guanxi and organizational dynamics: Organizational networking in Chinese firms. Strategic Management Journal, 22, 455-477. doi:10.1002/smj.167.

Pierce, J. L., Gardner, D. G., Dunham, R. B., \& Cummings, L. L. (1993). Moderation by organization-based self-esteem of role condition-employee response relationships. Academy of Management Journal, 36, 271-288. doi:10.2307/256523.

Podsakoff, P. M., BacKenzie, S. B., Lee, J., \& Podsakoff, N. P (2003). Common method biases in behavioral research: A critical review of the literature and recommended remedies. The Journal of Applied Psychology, 88, 879-903. doi:10.1037/ 0021-9010.88.5.879.

Rosenberg, M. (1965). Society and the adolescent self-image. Princeton, NJ: Princeton University Press.

Sager, J. K. (1991). Reducing sales manager job stress. Journal of Business and Industrial Marketing, 6, 5-14. doi:10.1108/EUM 0000000002750.

Samad, S. (2007). Social structure characteristics and psychological empowerment: Exploring the effect of opening personality. Journal of American Academy of Business, 12, 70-76.

Spiro, R. L., \& Weitz, B. A. (1990). Adaptive selling: Conceptualization, measurement, and nomological validity. Journal of Marketing Research, 27, 61-69. doi:10.2307/3172551.

Sujan, H. (1986). Smarter versus harder: An exploratory attributional analysis of salespeople's motivation. Journal of Marketing Research, 23, 41-49. doi:10.2307/3151775.

Sujan, H., Weitz, B. A., \& Kumar, N. (1994). Learning orientation, working smart, and effective selling. Journal of Marketing, 58, 39-52. doi:10.2307/1252309.

Taylor, S. E., \& Brown, J. D. (1988). Illusion and well-being: A social psychological perspective on mental health. Psychological Bulletin, 103, 193-210. doi:10.1037/0033-2909.103.2.193. 
Wang, C. L. (2007). Guanxi vs. relationship marketing: Exploring underlying differences. Industrial Marketing Management, 36, 81-86. doi:10.1016/j.indmarman.2005.08.002.

Weiner, B. (1980). Human motivation. New York, NY: Holt, Rinehart and Winston.

Weitz, B. A. (1978). Relationship between salesperson performance and understanding of customer decision making. Journal of Marketing Research, 15, 501-516. doi:10.2307/3150621.

Weitz, B. A., Sujan, H., \& Sujan, M. (1986). Knowledge, motivation, and adaptive behavior: A framework for improving selling effectiveness. Journal of Marketing, 50, 174-191. doi:10.2307/ 1251294.

Wells, L. E., \& Marwell, G. (1976). Self-esteem: Its conceptualization and measurement. Beverly Hills, CA: Sage.

Yang, M. M. (1994). Gifts, favors, banquets: The art of social relationship in China. Ithaca, NY: Cornell University Press.

Zhang, J., \& Bond, M. H. (1998). Personality and filial piety among college students in two Chinese societies: The added value of indigenous constructs. Journal of Cross-Cultural Psychology, 29, 402-417. doi:10.1177/0022022198293002. 